\title{
Mudanças na educação médica e residência médica no Brasil
}

Laura Feuerwerker ${ }^{1}$

FEUERWERKER, L. C. M. Changes in medical education and medical residency in Brazil. Interface - Comunicação, Saúde, Educação, v. 2, n.3, 1998

This essay seeks to identify the main movements and tendencies in medical education in Brazil over the last thirty years and, within this framework, to understand the process of social structuring of Medical Residency as well as its potential role with regard to the proposals of change in that area. Initially, the author describes the current status of the structural health-care crisis as well as the transformations it forces upon the medical profession. This is followed by a survey of the history, over the last thirty years, of the movements concerning the changes in medical education in this country, and their interconnection with Latin American and world movements. Finally, the author offers a profile of Medical Residency in Brazil, particularly in São Paulo, over the same period of time.

KEY WORDS: medical residency, medical education, education

Este ensaio busca identificar os principais movimentos e tendências da Educação Médica no Brasil nos últimos trinta anos, e, nesse marco, entender o processo de construção social da Residência Médica e seu potencial de articulação com as propostas de mudança na área. Inicialmente, caracteriza-se a conjuntura atual de crise estrutural da saúde e as transformações que ela impõe à profissão médica. Depois, recuperam-se os últimos trinta anos de história dos movimentos de mudança na educação médica no país, sua articulação com movimentos latino-americanos e mundiais. Segue-se uma caracterização da Residência Médica no Brasil, e particularmente em São Paulo, no mesmo período.

PALAVRAS-CHAVE: residência médica, educação médica, formação.

\footnotetext{
${ }^{1}$ Consultora da Fundação Kellogg no Brasil para o Programa UNI e da Fundação do Desenvolvimento Administrativo - Fundap, para residência médica. E-mail: lcmf@wkkf.org.
} 
Problemas conceituais das propostas de mudança na Educação Médica $1960-80$

A partir de uma reconstituição histórica das propostas de mudança na educação médica no Brasil, procurou-se identificar problemas conceituais que podem ter contribuído para o seu fracasso e apontar elementos significativos para o sucesso de propostas em construção.

Um primeiro problema das propostas de mudança até o final da década de 80 teria sido a dificuldade em traduzir para o campo da educação médica as insuficiências e dificuldades da prática médica e da organização dos serviços de saúde (diagnosticadas de maneira parcial e incipiente) (Schraiber, 1989). Como traduzir em novos conteúdos de ensinoaprendizagem, em novas maneiras de pensar e organizar os currículos a possibilidade de organizar serviços de saúde mais acessíveis e eficientes, mais humanos e democráticos?

Outra questão importante foi o fato de durante um longo período não se ter conseguido estabelecer a distinção entre a importância da formação geral de um médico na graduação (independentemente de sua inserção futura no mercado de trabalho) e a formação do médico geral, generalista etc. Toda a análise crítica a respeito do impacto negativo da introdução de especialidades já na graduação em função da fragmentação excessiva do conhecimento ficou perdida em meio a uma discussão ideologizada a respeito do médico a ser formado (na verdade, um debate sobre qual deveria ser o papel social do médico).

Um terceiro problema foi a subestimação da importância de trabalhar por transformações dentro das escolas médicas motivada pela convicção de que era preferível agir no outro prato da balança, a organização dos serviços de saúde e a prática assistencial, já que um teria maior poder de determinação sobre o outro. As práticas sanitárias e a organização do sistema de saúde e o mercado de trabalho exercem influência decisiva sobre o perfil e o conteúdo da formação dos médicos. Mas é preciso buscar influir nesse processo de formação durante todo o tempo e em todas as oportunidades: é necessário criar pontos de contato, elementos de identificação, possibilidades de discussão com o maior número possível de médicos. É preciso criar uma massa crítica que possa atuar nos dois terrenos: o da educação e o da prática e, sobretudo, não parece possível promover mudanças em qualquer desses terrenos prescindindo da participação de parte significativa da categoria médica.

Outro problema relevante foi a insuficiência da abordagem dos problemas propriamente pedagógicos da educação médica. As estratégias de mudança, apesar de partirem da identificação correta de problemas nessa área, não foram capazes de produzir/reunir conhecimento consistente que de fato contribuísse para a superação das dificuldades apontadas. A dificuldade em articular as disciplinas básicas e a clínica, a distinção do processo de capacitação em metodologia científica e no raciocínio clínico poderiam corresponder a um problema conceitual, epistemológico, não claramente respondido, significativo das estratégias de mudança na 
educação médica.

Também considerado relevante na formulação das estratégias foi o problema da super-valorização de simples mudanças de cenário de aprendizagem como agentes de transformação dos conteúdos ensinados $e$ aprendidos: a prática mostrou que não bastou ao estudante ser exposto à realidade, à miséria e à maneira de operar dos serviços para que se conseguisse interferir de fato na essência de seu processo de formação.

A introdução de novos cenários de ensino pode desempenhar um papel fundamental na mudança do perfil dos profissionais formados, contribuindo para concretizar esse conceito mais amplo de saúde, desde que venha acompanhada de mudanças nas práticas de saúde.

Existe uma nova dimensão de atuação profissional dada pela possibilidade de se construir saúde de uma outra maneira, de se estabelecerem outras/ novas relações entre as diferentes profissões da saúde e entre os profissionais e a comunidade. Em verdade, há novas práticas a construir dentro mesmo de cada um dos níveis de atenção, desde que se considere/ admita que todos os profissionais têm uma contribuição significativa a dar e que a população/os pacientes podem e devem ter um papel ativo nesse processo.

Outro obstáculo enfrentado nos processos de mudança foi imaginar ser possível produzir mudanças na escola médica a partir de um ou alguns departamentos isolados (Preventiva, Pediatria e raramente GinecologiaObstetrícia). Essa dificuldade foi ainda agravada pelo fato de existir uma fratura entre os departamentos de Medicina Preventiva, Medicina Social $e$ depois Saúde Coletiva em relação aos demais departamentos e em relação à categoria médica de modo geral.

Esse hiato foi criado em decorrência da desqualificação da prática clínica e do trabalho médico em geral, em que muitas vezes se incorreu quando da crítica à abordagem biologicista $e$ centrada na doença da medicina flexneriana.

A tentativa de incorporar ao trabalho médico a formação para a saúde (que costuma ser identificada com as atividades de prevenção e promoção) muitas vezes levou à desqualificação da prática clínica, por ela ser centrada na abordagem ao paciente através da doença (Campos,1994). Como atualmente as bases do conhecimento e dos métodos de trabalho do médico repousam sobre o raciocínio clínico, que tem a doença como objeto, esse tipo de questionamento envolve a necessidade de reformulação das bases desse conhecimento. E essa certamente não é uma discussão

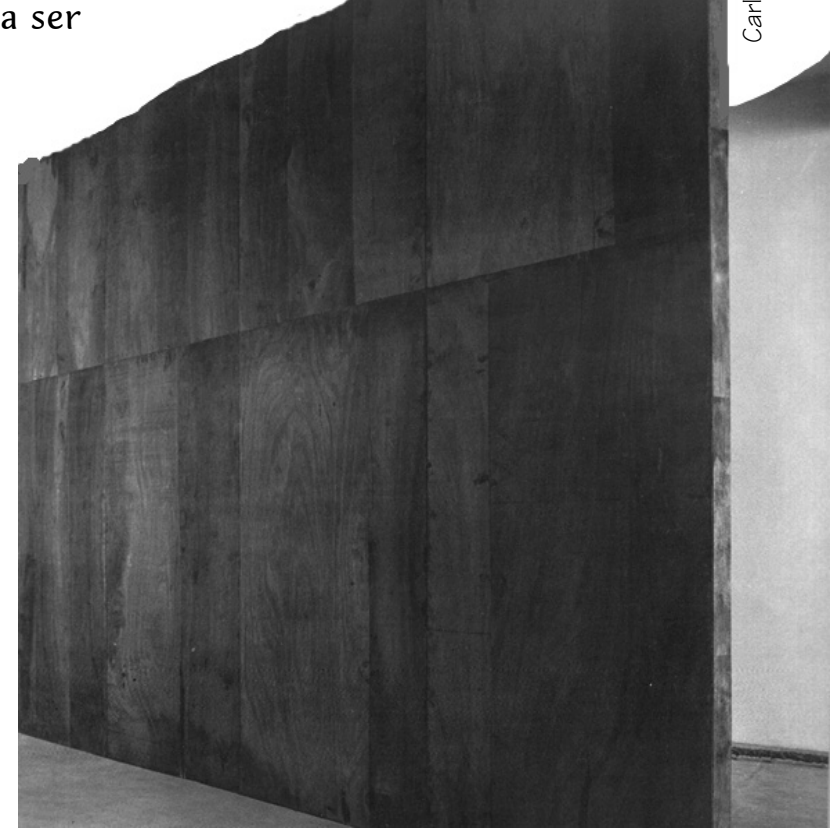


já suficientemente desenvolvida.

Também a crítica ao atendimento individual levou freqüentemente à desqualificação da prática clínica. Por mais que as condições de vida e a inserção do indivíduo na sociedade sejam fundamentais na determinação do processo saúde-doença, quando o indivíduo adoece, sua dor e seu sofrimento são de ordem privada. Ver a doença como fenômeno social possibilita ações sobre o coletivo, mas atender a um doente também exige ações individuais. Como abordar o doente e qual o papel do médico no domínio do combate social à doença não são tampouco questões esgotadas.

A insuficiência da abordagem crítica à medicina científica em responder a essas questões provocou uma quase impossibilidade de diálogo entre os representantes da saúde coletiva e o restante da categoria médica, inviabilizando qualquer iniciativa de mudança que partisse desses departamentos ou dessas correntes.

Outro elemento significativo foi a insuficiência das propostas de integração docente-assistencial na valoração da necessidade da mudança de práticas, das relações entre profissionais de saúde, das relações entre médicos e pacientes (Marsiglia,1995). Além de ser uma questão fundamental na construção de um novo modelo assistencial, é também ponto crucial no desenvolvimento de novos conteúdos e novas experiências de ensinoaprendizagem durante o processo de formação e definição do perfil dos profissionais de saúde.

Outro problema apontado foi a reduzida capacidade de influência sobre o ensino médico que a introdução de disciplinas como a Sociologia, as chamadas ciências do comportamento e outras demonstrou ter. Uma primeira razão foi a perspectiva com que essas disciplinas foram introduzidas. Assim como ocorre em outras especialidades, não se procurou identificar quais conteúdos dessas disciplinas seriam essenciais e úteis à formação dos médicos. Um outro equívoco foi imaginar que a incorporação de um conceito mais complexo de saúde e de elementos do instrumental sociológico à construção do raciocínio clínico e à prática médica pudesse corresponder a uma mudança do eixo epistemológico da medicina (a Sociologia passaria a ser um de seus eixos constitutivos). A compreensão da causalidade social da doença implica abordar a saúde dentro do contexto social, implica buscar ações intersetoriais, implica construir saúde socialmente, mas não implica negar a necessidade de curar doenças. Compreender a causalidade social da doença deve auxiliar o médico a construir seu raciocínio e até a aumentar a eficiência de suas propostas terapêuticas, mas não o transforma em um sociólogo.

Considera-se que o perfil da atividade médica vai mudar ao se transformarem suas relações com os pacientes e com os demais profissionais da saúde. Ou seja, o médico deve ter em sua formação elementos indispensáveis para que compreenda a complexidade de certos problemas $e$ seja capaz de reconhecer a necessidade de trabalhar em equipe, mas não deixará de ser médico, nem se transformará em um super-profissional.

Os limites das propostas para mudanças na educação médica até o final da década de 80 estão demonstrados concretamente por sua incapacidade de produzir mudanças reais. O discurso é recorrente, algumas vezes reelaborado, mas impotente. 


\section{A potencialidade dos projetos atuais de mudança na educação médica}

A partir do final dos anos 80 , as iniciativas de propor mudanças na educação médica multiplicaram-se e ganharam força. A crise da saúde e a crise de identidade da corporação médica produzidas pela capitalização do setor saúde contribuíram decisivamente para a intensificação desse processo.

No Brasil, o processo de implantação do Sistema único de Saúde - SUS, tradução na prática do movimento pela Reforma Sanitária, está-se dando de maneira paradoxal, como refere Campos (1994):

Por um lado, a crise de financiamento do sistema de saúde está
provocando uma parcial e desordenada desativação de leitos
hospitalares em todas as especialidades (...) Por outro lado, há um
esforço ordenado, um projeto geral, voltado para a criação de
alternativas assistenciais em vários campos que vem se implantando
em ritmo lento e ainda com um empuxe pequeno, a ponto de não
haver logrado redirecionar os recursos públicos aplicados em saúde.

O SUS está sendo construído no interior, e a partir de um sistema de saúde regido por lógicas muito distintas das propostas de universalidade, eqüidade e integralidade da assistência. A necessidade de superar certas limitações e problemas existentes em suas formulações, assim como de reconstituir sua base de sustentação começou a ser apontada por diferentes autores (e sujeitos).

\footnotetext{
Várias experiências político-administrativas recentes têm se demonstrado impotentes para alterar o status-quo, na medida em que não conseguiram favorecer a produção de sujeitos sociais competentes para dar sustentação e prosseguimento a mudanças institucionais (Campos, 1994).

Mais importante que retocar, atualmente, "imagens-objetivo" da Reforma Sanitária Brasileira, é iniciar processos, constituir sujeitos sociais que possam dar conta dos novos desafios impostos pela realidade. E a formação de recursos humanos e a educação médica em particular não podem ser negligenciados enquanto espaços de constituição desses sujeitos, ainda que não exclusivos (Paim, 1995).
}

Não se pode supor que a solução para a crise paradigmática da saúde vá surgir a partir de projetos de mudança na educação médica. Ou que os problemas enfrentados na implantação do SUS possam encontrar sua solução na discussão sobre a formação de recursos humanos. Nos dois casos, a solução depende de haver uma mudança na maneira como a sociedade enfrenta a construção da saúde. Mas o processo de produção de alternativas ocorrerá nos dois campos: educação e prática. E os processos de mudança deverão ter um grau de simultaneidade. É parte da dialética das transformações. 
${ }^{2}$ Comissão

Interinstitucional Nacional de Avaliação do Ensino Médico (CINAEM) desencadeou a partir de 1991 um movimento de autoavaliação do ensino médico no Brasil. Na fase atual o processo conta com a

participação de 48 das 80 escolas médicas e já se produziram estudos sobre o corpo docente $e$ os estudantes (Gallo, 1996; Piccini, 1997).

3 A Iniciativa UNI é apoiada pela Fundação Kellogg e abrange 23 projetos em 11 países da América Latina, em que se procura desenvolver uma parceria entre a universidade, os serviços de saúde e a comunidade com o objetivo de produzir mudanças na educação dos profissionais de saúde, na organização e no funcionamento dos serviços de saúde e na participação da comunidade nas decisões que interferem em sua qualidade de vida (Kisil e Chaves, 1994; Feuerwerker, 1996; Kisil, 1996).

${ }^{4}$ Agenda for Action é uma iniciativa da Divisão de Recursos Humanos da Organização Mundial da Saúde, que propõe uma ação coordenada de escolas médicas em articulação com associações profissionais médicas para buscar uma melhoria na qualidade e cobertura dos serviços de saúde, assegurar a relevância $e$ a qualidade da educação e da pesquisa, implementar processos de aprendizagem eficientes e comprometer-se com os processos de garantia de qualidade $e$ avaliação tecnológica. (World..., 1991)
Uma das vertentes alternativas (em processo de construção) é a que propõe a introdução do paradigma da saúde em contraposição ao paradigma da doença. Segundo essa proposição, o processo de construção social da saúde, baseada na ação intersetorial e na crescente autonomia das populações em relação à saúde, é que deveria passar a ser central, reorientando as relações entre profissionais de saúde e comunidade e redefinindo o peso e o papel do setor de prestação de serviços de saúde nesse processo (Mendes, 1996).

Não existirá apenas um projeto de superação da crise. Este é um momento apropriado à emergência de novas teorias.

O momento de crise é favorável à gestação de alternativas. As propostas de mudanças na educação médica analisadas até aqui tiveram provavelmente o limite histórico que as antecipações enfrentam, por isso são parciais, incompletas e não conseguiram a adesão indispensável às transformações desejadas.

Algumas das propostas de mudança da educação médica mais recentes, ainda em processo de construção na prática, revisitando criticamente as experiências anteriores, podem estar desenhando um caminho mais favorável a transformações substantivas. Farei referência a quatro propostas presentes de alguma maneira no cenário nacional: o movimento desencadeado pela CINAEM ${ }^{2}$, a proposta UNI ${ }^{3}$, "Agenda for Action" ${ }^{4}$ da OMS e a proposta de Gestão de Qualidade na Educação Médica ${ }^{5}$ da OPS. Destacarei apenas alguns elementos que parecem mais significativos por abordar temas essenciais ao processo de mudança e por serem distintivos em relação às propostas anteriores.

Em primeiro lugar, algumas dessas propostas dirigem-se não somente à educação médica, mas ao conjunto das profissões da saúde (importante, porque a crise é da saúde e não simplesmente da medicina, e envolve necessariamente a redefinição das relações e papéis das distintas profissões). Em segundo lugar, aponta-se a necessidade imperiosa de um compromisso institucional com o processo de mudança (refletindo a preocupação de criar alternativas que tenham possibilidade real de implantação, que se traduzam em ação potente e que envolvam a maior parte das disciplinas nas escolas médicas).

A articulação com os serviços de saúde não é vista como circunstancial. 
${ }^{5}$ Gestão de Qualidade na Educação Médica foi uma proposta apresentada pela Organização Panamericana de Saúde em 1991, que propunha a gestão estratégica de qualidade para desencadear um processo de mudança nas escolas médicas (Organización..., 1994).
Ela é essencial e a percepção de problemas e a construção de soluções se daria simultaneamente, numa relação dialética, num processo interpenetrado (os serviços de saúde são os locais onde se desenvolvem as práticas de saúde, alvo estratégico de mudanças capazes de transformar a lógica de um sistema). Pela primeira vez também as estratégias apontam a necessidade de a comunidade/pacientes participarem desse processo como atores essenciais (já que necessariamente terá que existir uma redefinição dos papéis dos diferentes sujeitos no processo de construção da saúde).

Há heterogeneidade na maneira como as referidas estratégias tratam essas questões.

A CINAEM, utilizando a avaliação como instrumento de transformação, trabalha, ainda que de maneira não muito elaborada, a necessidade do compromisso institucional com a avaliação e com as propostas de mudança, a importância da construção de consensos nesse processo, a necessidade de articulação com "a sociedade civil". O maior mérito da CINAEM tem sido sua capacidade de envolver no movimento voluntário de auto-avaliação um número significativo de escolas médicas brasileiras. Como a orientação dos processos de mudança eventualmente desencadeados pela avaliação é, de certo modo, fluida, há a possibilidade de projetos mais estruturados ganharem espaço na produção de soluções para os problemas encontrados nas escolas.

A "Agenda for Action" da OMS têm a preocupação de incentivar a articulação das escolas médicas com outros setores sociais e com outros atores do cenário da saúde, considerando que somente uma interação mais ampla poderá gerar alternativas para uma nova maneira de encarar a saúde. É uma proposição flexível, que possibilita a interação com as demais propostas de mudança.

A OPS enfrenta uma crise por conta da redefinição do papel (e do poder) de organismos internacionais no contexto pós-guerra fria. Como conseqüência, decidiu suspender a publicação da revista "Educación Médica y Salud", que era a única publicação latino-americana sobre educação médica (e de profissionais de saúde). Apesar disso, e de estar relativamente enfraquecida (e empobrecida), a OPS tem procurado manter-se ativa no cenário da educação médica. Como já foi dito, não houve iniciativas de concretização da proposta de qualidade, mas a organização tem procurado viabilizar a articulação das forças comprometidas com mudanças para a educação médica pela iniciativa chamada "Educación Médica Permanente en beneficio de la equidad y calidad de la respuesta social en Salud en América Latina y Caribe", que pode tornar-se também um espaço de intervenção .

A iniciativa UNI parece articular mais claramente os elementos estratégicos aqui apontados. A modalidade de associação entre universidade, serviços de saúde e comunidade proposta pelo programa UNI é um de seus aspectos mais inovadores. É uma relação de parceria, que pressupõe uma distribuição real de poder entre esses segmentos e que possibilita a constituição de novos atores num exercício prático de construção de novas maneiras de produzir saúde. Os serviços de saúde e os espaços comunitários revelam-se como os cenários privilegiados desse processo de experimentação, que envolve a comunidade, os profissionais dos serviços, 


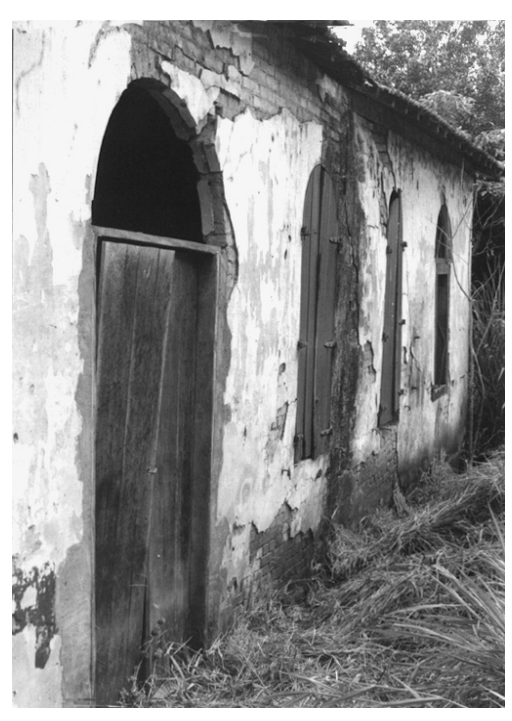

estudantes e professores, todos redesenhando seu papel na construção da saúde e na produção de conhecimento sobre saúde, propiciando a constituição de novos sujeitos sociais.

Uma das principais qualidades dessas propostas mais recentes é conectar a mudança na educação médica com movimentos sociais de transformação. Este é o elemento que pode torná-las potentes. A proposta UNI é a que utiliza essa estratégia de maneira mais clara: a parceria entre universidade, serviços de saúde e comunidade conecta os movimentos pela construção de um novo sistema de saúde e pela democratização da participação popular com as mudanças na formação profissional.

\section{O papel da residência na formação médica}

Atualmente $70 \%$ dos médicos que se formam têm a oportunidade de freqüentar um programa de Residência. Não está disponível o número exato de vagas preenchidas em todo o país, mas tomando São Paulo como referência, pode-se supor que pelo menos $60 \%$ dos médicos que se formam a cada ano ingressem em programas de Residência Médica (Fundap,1996).

É importante, então, buscar compreender o papel que a Residência Médica tem hoje na formação dos médicos no Brasil. São fartos os depoimentos atribuindo a ela um duplo papel na formação dos médicos. Complementar o processo de graduação, tendo em vista as deficiências amplamente reconhecidas desse processo. E também oferecer a especialização como uma possibilidade de melhor inserção no mercado de trabalho, constituindo uma forma específica de ingresso no mercado.

É possível levantar a hipótese de que a importância da Residência no processo de formação dos médicos seja maior e distinta. A Residência Médica parece ter se convertido no momento que mais fortemente marca o perfil profissional dos jovens médicos.

A hipótese da Residência funcionar como facilitador de uma inserção privilegiada no mercado necessita ser melhor discutida. Esse fenômeno é em parte verdadeiro, principalmente para os médicos que conseguem freqüentar um programa de Residência em instituições de renome, como as universitárias de maior tradição. Não se pode dizer o mesmo a respeito dos que freqüentam os programas mantidos pela maior parte das instituições de serviço.

Grande parte dos egressos dos programas de Residência exercem atividades profissionais em outras áreas que não a de sua especialização (o que é esperado, considerando que não estão operando mecanismos eficientes de concatenação entre a formação de especialistas e as necessidades do mercado público e privado), mas esse fato desqualifica em parte essa "inserção privilegiada" no mercado.

O processo de deterioração salarial dos médicos em nosso país é patente e causador da multiplicidade de empregos simultâneos desses profissionais. São esses mesmos médicos especialistas que se submetem ao aviltamento salarial (já que quase $60 \%$ dos médicos brasileiros declararam ter título de especialista, como revela a pesquisa sobre o perfil do médico) (Machado, 1996). Este é mais um elemento de desqualificação dessa "inserção 
privilegiada" no mercado.

A Residência Médica como forma específica de ingresso no mercado também merece melhor discussão. Considerando o nível de deterioração do mercado de trabalho médico, seria de se esperar que não houvesse vagas ociosas na Residência. Não é o que acontece. Muito embora haja casos de residentes que ingressam em programas de baixa procura exatamente para garantir um período de dois anos de remuneração segura, de modo geral não é esse o comportamento dos recém-formados.

A ociosidade de vagas é função das especialidades e também das instituições. Tanto assim que em São Paulo, conforme já apresentado, a taxa de preenchimento das vagas de RI nas áreas básicas é de $71,1 \%$ e oscila de 77 a $85 \%$ nas especialidades clínicas, cirúrgicas e nos métodos diagnósticos. Também em São Paulo, as universidades estaduais e alguns hospitais de maior prestígio têm taxas de preenchimento variando entre 85 e $95 \%$, enquanto os hospitais de menor prestígio da rede apresentam taxas entre 53 e $60 \%$. Ou seja, os recémformados não utilizam a Residência como possibilidade de ocupação a qualquer preço (Fundap, 1996).

Devemos buscar, então, explicações adicionais para a procura dos médicos recém-formados pela Residência. Surge como alternativa importante a necessidade de complementação da formação de graduação. Há dois elementos que podem auxiliar na compreensão desse fenômeno: a importância histórica da prática no processo de formação do médico e as conseqüências da especialização crescente nesse mesmo processo de formação.

A prática profissional historicamente tem sido transmitida

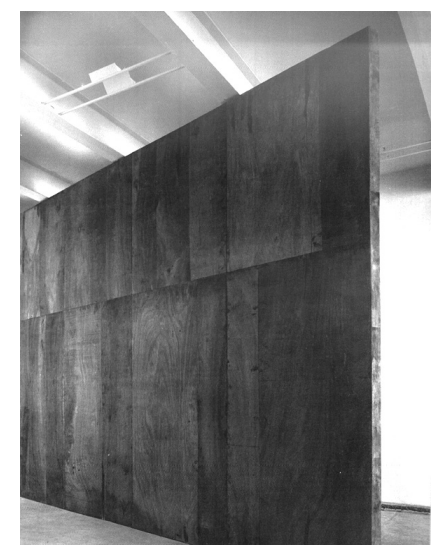
através de treinamento em serviço. É no processo de combinar os conhecimentos teóricos adquiridos com a experiência clínica (indicando relacionamento com pacientes) que se encontra a "mágica" da prática profissional médica. Somente a experiência adquirida na prática pode completar a formação (científica) do médico: é pela experiência clínica que o profissional se apropria dos doentes (e não mais apenas das doenças). É pela prática que se constrói a experiência clínica e é mediante o aprendizado em serviço que o futuro profissional constrói também a ética de suas relações com os pacientes, baseada no exemplo e na experimentação.

A clínica é o instrumento de articulação da patologia ao conhecimento da subjetividade dos pacientes, pois na clínica estão presentes várias dimensões de subjetividade: sintomas, reação ao sofrimento e à dor, situação de vida etc. Se o conhecimento científico é essencial à construção de hipóteses, a prática clínica é essencial para exercitar a capacidade de apreensão da realidade. $\mathrm{E}$ essa é uma habilidade que se adquire e exercita na prática concreta, no exercício acumulado (Schraiber,1993, descrevendo a prática médica no período da medicina liberal). 
Sabe-se que o corpo científico de conhecimentos necessário à construção do saber médico tem sofrido ampliação ininterrupta no processo de desenvolvimento científico e tecnológico. Sabe-se também que a reconstrução da autonomia profissional médica baseou-se no acúmulo e na intensidade da cientificidade possibilitada pela incorporação de tecnologia. Ora, a utilização progressivamente mais intensa de tecnologia na prática médica torna mais objetiva (e científica) a apreensão da realidade pelo médico e as suas intervenções sobre ela, mas não elimina a necessidade de construir um raciocínio clínico, nem de considerar as necessidades subjetivas do paciente. Persiste, portanto, a necessidade do treinamento clínico.

O treinamento prático dos estudantes de medicina inicia-se, na realidade, no internato, obrigatório nas escolas médicas brasileiras. E é provavelmente durante esse processo que se dá a primeira diferenciação na qualidade básica da preparação dos médicos pelas diferentes escolas. Apesar de poder marcar o perfil e a qualificação do médico recém-formado, o treinamento ao nível de internato não tem sido suficiente para garantir a terminalidade do curso médico. Apontam-se como possíveis motivos para a insuficiência da graduação exatamente os processos de especialização e de incorporação tecnológica.

$\mathrm{O}$ volume e a profundidade de informações geradas a partir do desenvolvimento das especialidades produzem uma fragmentação do conhecimento que prolonga/retarda seu processo de integração pelos estudantes na graduação. Da ação da insulina sobre os receptores celulares ao paciente diabético e da bomba de sódio e potássio ao coma por edema cerebral há uma grande distância. O raciocínio fisiopatológico, hoje, envolve a utilização de conhecimentos complexos, cuja articulação não é simples, nem automática.

A multiplicação de procedimentos, também trazida pelo processo de especialização e de utilização tecnológica, presentes na prática no internato, pode comprometer a possibilidade real de adestramento prático do estudante. Multiplicaram-se os procedimentos mínimos indispensáveis $e$, conseqüentemente, reduziram-se as oportunidades de experimentá-los $e$ executá-los da maneira e na intensidade adequadas (ou seja, fazer muitas vezes). Todos os graduados devem saber interpretar um eletrocardiograma? Ou devem solicitar uma consulta ao cardiologista sempre que precisarem utilizar esse recurso diagnóstico (atualmente disponível em muitas unidades básicas)? A mesma pergunta se aplica ao raio $X$ simples de tórax. Ou esses procedimentos não são necessários na prática clínica desenvolvida na rede de atenção primária?

É preciso considerar a hipótese de que, dado o nível atual de desenvolvimento técnico e científico, a formação geral do médico na graduação não seja capaz de assegurar o nível necessário de treinamento nas atividades práticas de todas as áreas básicas (pelo menos da maneira como a graduação está organizada atualmente). $\mathrm{O}$ treinamento na Residência, dentro já de uma especialidade (o que reduz o escopo da área de aprendizagem), pode ter se transformado em uma das alternativas para viabilizar a incorporação de 
conhecimentos tão específicos.

Também a existência de um rico arsenal de propedêutica armada reduziu, como já se viu, a oportunidade (e a necessidade aparente) de contato entre o médico (estudante) e os pacientes. A introdução da tecnologia e da propedêutica armada corresponde a um processo de objetivação da apreensão da realidade pelo médico. Mas a perda de qualidade e intensidade da relação entre médico (estudante) e paciente poderia comprometer o "potencial de apreensão" da clínica, do raciocínio clínico e do paciente nos estágios práticos existentes. O estudante necessitaria de mais tempo, de um maior número de contatos para desenvolver e aperfeiçoar seus "mecanismos de apreensão".

É exatamente por dar continuidade a esse processo de formação iniciado no internato, por combinar a aquisição de conhecimentos especializados mediante um treinamento prático em serviço, que a Residência Médica adquire relevância na educação dos médicos. A diversidade de experiências práticas que a Residência propicia (em relação a casos, cenários, exames, condutas, procedimentos), associada a uma atividade teórica de sistematização e a níveis crescentes de autonomia (sem estar abandonado à própria sorte) parece compor um estágio eficaz (e insubstituível no momento) do treinamento profissional do médico.

Além disso, é no processo de especialização, no treinamento prático que a Residência propicia, que se dá a verdadeira "iniciação profissional” do médico. Tanto que, para a inserção no mercado de trabalho, é mais importante e significativa a instituição onde os médicos fizeram seu processo de especialização do que a escola médica de origem.

Muito embora seja fenômeno presente desde a graduação, é principalmente pelos contatos propiciados pela Residência Médica que se compõem as relações profissionais, que surgem as oportunidades para os jovens médicos se integrarem às equipes de profissionais mais experientes $e$ ingressarem efetivamente no mercado. Esse certamente é um dos motivos que têm levado ao prolongamento dos programas de Residência: a inserção progressiva nos grupos, com a assunção também progressiva de responsabilidades e autonomia (dentro e fora do hospital de ensino).

A institucionalização da residência médica

O principal estudo sobre o processo de institucionalização da Residência Médica em nosso país considera que esta adquiriu papel fundamental como instrumento de prestação de serviços de saúde e que os residentes, como profissionais, passaram a ser atores fundamentais no mundo dos serviços de saúde (públicos e privados). Segundo Elias (1987) essa teria sido a tônica principal do processo de institucionalização da Residência Médica "no interior das Políticas de Saúde". A prestação de serviços teria assumido importância tão grande que comprometeria a caracterização da Residência Médica como processo educacional, já que a lógica da organização dos estágios obedeceria muito mais às necessidades dos serviços do que às de aprendizagem.

$\mathrm{O}$ autor considera também que, ao se articular às transformações 
ocorridas na prática médica e no mercado de trabalho, a Residência Médica passou a interessar a outros setores sociais que não os médicos. Caracteriza o momento de sua regulamentação como o marco inicial do processo de apropriação do Estado em relação à Residência e aponta a existência de um consenso, no interior do aparelho estatal, na definição da Residência como projeto educacional (a partir do qual buscava-se articulá-la às políticas de saúde). Na operacionalização da regulamentação, no entanto, haveria algumas divergências, que teriam levado, por exemplo, ao abrandamento das relações da Residência Médica com a pós-graduação.

O tempo permite analisar algumas dessas questões com outros olhos. Qual seria exatamente o terreno em que aconteceu a institucionalização da Residência Médica? O exame das estratégias de mudança da educação médica e das políticas oficiais nessa área revela que a Residência Médica não chegou a ser alvo das preocupações desses setores. Nem tampouco chegou a ser objeto de formulação dos responsáveis pelas políticas de saúde, apesar do papel relevante que os residentes têm na prestação dos serviços e da importância de se definir uma política para a formação dos recursos humanos da saúde, médicos em particular. Nem mesmo governos e secretarias estaduais que investem recursos e têm poder real para definir políticas em relação à Residência Médica tomaram a iniciativa de utilizar esse poder e interferir no processo.

A Residência Médica no Brasil, portanto, apesar de institucionalizada, potencialmente sobre controle dos Ministérios da Educação e da Saúde e de outras autoridades dessas áreas, tem tido seus rumos definidos pelas instituições que mantêm os programas, pelo mercado de trabalho, em uma relação mediatizada pelos interesses da corporação médica: médicosresidentes, sociedades de especialistas e outras entidades. Há várias evidências sobre isso desde a criação da Comissão Nacional de Residência Médica - CNRM, que foi, de fato, o único momento em que o Estado interveio claramente no processo.

A CNRM estabeleceu, no processo de regulamentação da Residência Médica, requisitos e condições mínimas para o processo pedagógico e de trabalho, reconheceu o residente como trabalhador (mas autônomo, sem reconhecimento do vínculo empregatício com a instituição que mantém o programa). Foi determinado um piso salarial, mas na forma de uma bolsa de estudos. Outros direitos trabalhistas, como férias, licença-maternidade, foram também assegurados ao longo do tempo.

Como se vê, apesar de a Residência Médica ser regulamentada por uma Comissão abrigada no MEC e reconhecida formalmente como processo educacional, na prática, a maior parte das reivindicações trabalhistas dos residentes foi atendida. Essa é uma evidência de acordo, de compatibilização de interesses, pois o Estado garantiu os direitos dos residentes - ao contrário do que gostariam as instituições mantenedoras de programas - mas sem o reconhecimento completo da sua condição de trabalhadores.

O certificado conferido pelos programas de Residência Médica foi elevado à categoria de título de especialista, reconhecido pelo MEC, sem deixar de reconhecer como válidos os títulos aprovados pelas Sociedades de Especialistas. Esta é uma atitude que novamente evidencia acordo, pois se o 
governo não abriu mão de sua responsabilidade no processo de titulação como gostariam as sociedades de especialistas e a Associação Médica Brasileira - também não excluiu certo grau de autonomia dessas instituições no processo - como talvez preferisse o mercado.

A composição da CNRM é marcada pela presença das organizações da corporação médica - o que também evidencia acordo, pois o governo tomou a si a tarefa de regulamentação, mas deixou sua concretização a cargo do plenário da Comissão, composta pelas principais entidades representativas da categoria. E nunca mais o MEC ou o Ministério da Saúde ou qualquer outra autoridade interferiu nos trabalhos da CNRM.

Aparentemente, portanto, apesar de institucionalizada, a Residência Médica não escapou do âmbito da categoria médica do ponto de vista de suas definições. O governo criou a instância para que as negociações entre os vários segmentos médicos ocorresse.

A importância que a Residência Médica tem para a categoria é confirmada por outros dados da realidade. A intensa procura da Residência pelos médicos recém-formados (os dados já apresentados são eloqüentes) e a oferta (sempre crescente) de vagas e programas é um deles. O tipo de articulação que ocorre dentro da CNRM, em suas relações com as diversas entidades de classe da categoria médica e com o Congresso Nacional é outro. Há uma articulação que tem viabilizado decisões curiosas como, por exemplo, a preservação do piso salarial nacional dos residentes. Ou seja, a Residência parece ser um momento tão precioso no processo de formação do profissional médico que o piso nacional resiste a todos os conflitos que potencialmente poderiam ser gerados pela própria categoria (em função das discrepâncias salariais entre residentes e preceptores). E, por outro lado, o tema Residência foi deixado tão exclusivamente ao sabor da categoria que o piso ainda persiste nesta conjuntura fortemente marcada pela desregulamentação:

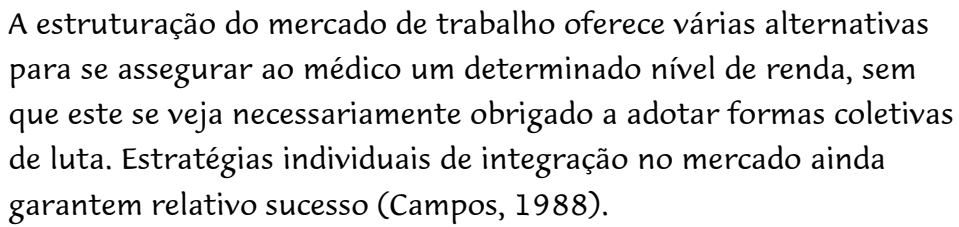

A Residência pode estar cumprindo um papel fundamental, talvez como um instrumento (coletivo) de autodefesa da categoria médica, que detém, assim, o controle sobre uma etapa fundamental de seu processo de formação.

O perfil do profissional formado pelos programas de Residência Médica é definido pelas características de cada uma das instituições formadoras, conectadas ao heterogêneo mercado de trabalho real. As tendências do mercado interferem diretamente na demanda maior ou menor dos futuros residentes por esta ou por aquela especialidade (a queda da procura por Medicina Preventiva, Pediatria e Patologia e o crescimento da procura por programas na área de Radiologia e Métodos Diagnósticos deixam entrever claramente esse fenômeno). Mas a pressão do mercado não tem sido 


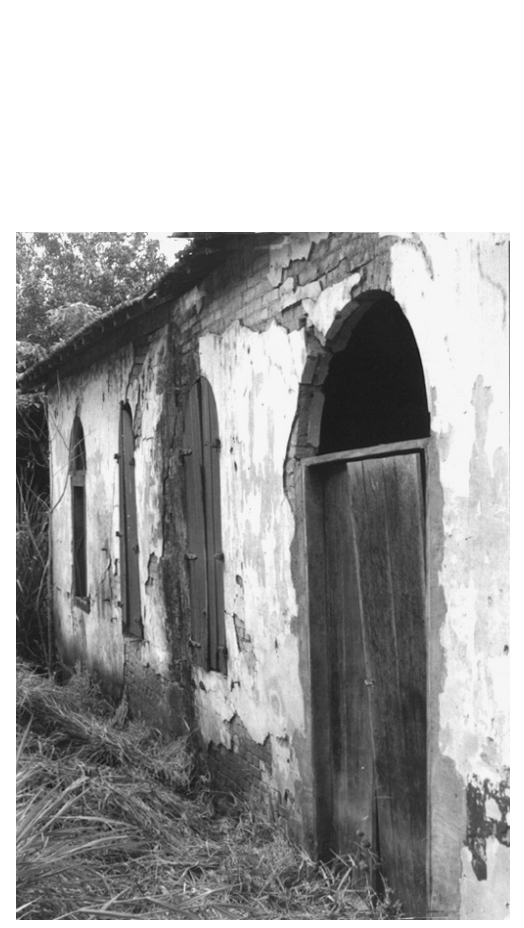

suficiente para vencer algumas barreiras impostas pela corporação: por exemplo, há escassez de médicos nas áreas de Otorrinolaringologia e Oftalmologia em todo o país, e no entanto as vagas destinadas a essas especialidades vêm apresentando um crescimento mínimo.

\section{A natureza da residência médica}

Outra questão fundamental é compreender a natureza da Residência Médica, ou seja, qual seria seu aspecto fundamental: o processo educacional ou o processo de trabalho? Segundo Elias (1987):

inúmeros autores, ao tomarem a Residência Médica como objeto de estudo, procedem referenciados numa concepção de Residência Médica como sendo um projeto educacional, destinado à especialização do médico. (...) Ao procederem desse modo, tais autores acabam por limitar as possibilidades de compreensão das questões postas pela Residência, advindas da complexidade que esta adquiriu a partir de sua integração às Políticas de Saúde. Disto provavelmente decorre o alcance restrito das propostas de intervenção objetivando o encaminhamento dos problemas enfrentados pela Residência. Assim, as propostas hoje colocadas para superar-se a subordinação dos aspectos educacionais da Residência aos interesses institucionais na prestação da assistência médica, freqüentemente cingem-se à reformulação do perfil curricular dos Programas. Sem se desconsiderar a necessidade de revisar alguns aspectos destes Programas, ressalta-se que ao se restringirem às questões curriculares, tais propostas, se de um lado representam melhores possibilidades de desenvolvimento dos programas, por outro, não dão encaminhamento ao problema central que as origina, vale dizer, a importância adquirida pela residência médica no sistema de prestação da assistência médica.

Adiante, como já foi referido, o autor afirma que o estudo das concepções básicas em relação à Residência permitiu identificar duas correntes, denominadas de "pedagógica " $e$ "trabalhista". Reconhecia que ambas apresentavam alguns elementos comuns, "destacando-se o caráter prescritivo na abordagem da Residência". Atribuía esses pontos comuns a um fato: "a resistência das duas correntes em aceitar a institucionalização da Residência no interior das Políticas de Saúde”.

\footnotetext{
Em relação à caracterização da Residência, desqualificam-se as pretensões das duas correntes. Apesar de poderem-se reconhecer na residência as dimensões educacional e a de trabalho, ela não se reduz ou esgota em nenhuma delas. Assim, a verdadeira característica, assumida pela residência, será dada pela interação dessas duas dimensões em situações institucionais concretas.
}

Analisando o problema dez anos depois, é possível afirmar que houve a 
correta identificação da complexidade da natureza da Residência Médica, simultaneamente de trabalho e de treinamento. Mas não ficou claro o que seria compreender a Residência em sua dupla dimensão. A caracterização das correntes identificadas como "pedagógica" e "trabalhista" não dá exatamente conta da realidade. Como o próprio autor aponta, as concepções se interpenetravam e variavam ao longo do tempo e ao sabor das situações concretas. Nesse trabalho, Elias não conseguiu formular claramente como a singularidade da Residência Médica poderia se traduzir do ponto de vista da política.

A tradução dessa singularidade poderia ser o reconhecimento $e$ valorização do papel do trabalho como instrumento fundamental do aprendizado na Residência Médica. Não existe contradição entre trabalho e aprendizado, nem subordinação de um processo ao outro. Um se faz dentro do outro, de maneira indissociável. O tratamento adequado à Residência Médica implicaria em reconhecer que ela é parte integrante e fundamental do processo de formação dos médicos, porém, intrinsecamente ligada à produção dos serviços de saúde. A Residência Médica estaria na interface (que é concreta e real) entre as políticas de educação médica e as políticas de saúde.

\section{Residência médica: propostas de mudança na educação médica e na Saúde}

No que então teria se transformado a Residência Médica? Segundo as reflexões aqui desenvolvidas, num momento privilegiado de treinamento clínico para a maior parte dos médicos no Brasil. Haveria, portanto, elementos para que a Residência passasse a ser encarada como parte integrante do processo de formação dos médicos e, por sua relevância no treinamento clínico, teria se convertido em um momento marcante na definição do seu perfil profissional.

No entanto, nenhuma das propostas de mudança na educação médica presentes no cenário nacional propõe qualquer intervenção no processo de formação na Residência e é necessário entender por que isso acontece. Para tanto, é útil retomar a discussão sobre a defesa da terminalidade do curso de graduação. Sem dúvida ela foi um ponto fundamental das propostas para a educação médica em nosso país e é possível identificar vários elementos de sua racionalidade.

Num primeiro momento, os países em desenvolvimento contavam com poucos médicos e poucas escolas. Os médicos que estavam sendo formados necessitariam estar prontos para ingressar imediatamente no mercado, pois havia grandes contingentes populacionais sem assistência. Depois do processo de multiplicação de escolas médicas, já não havia escassez de

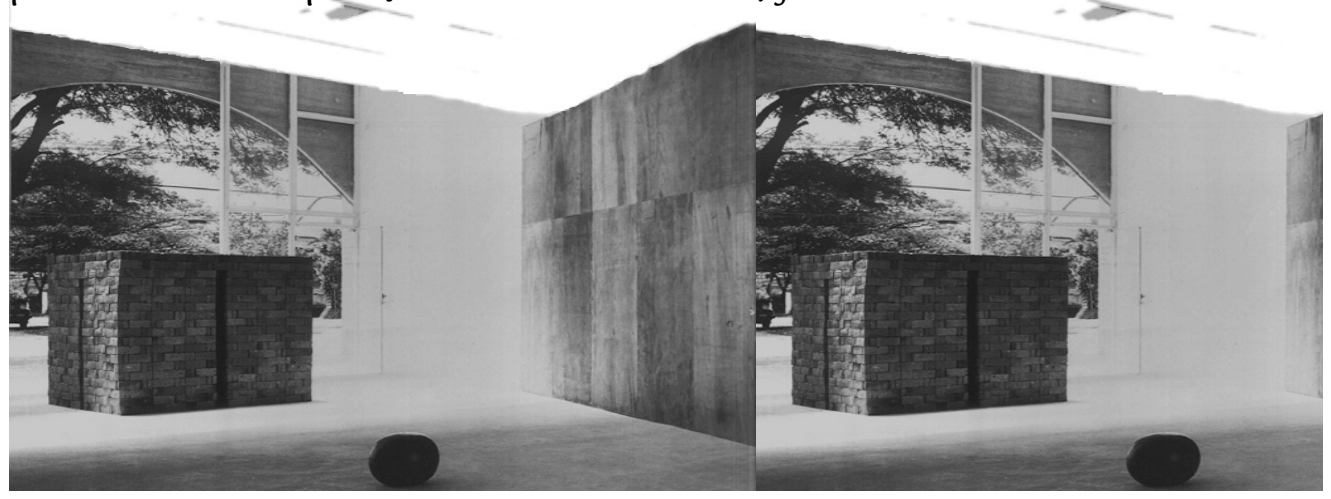




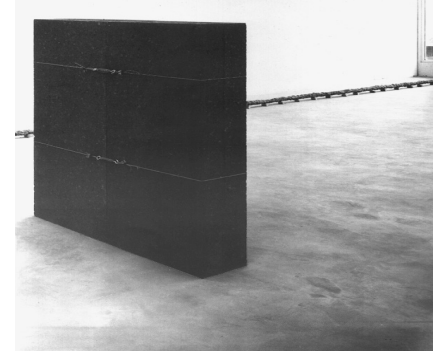

profissionais, mas o modelo de atenção continuava excludente. Então continuava necessário formar profissionais menos sofisticados, que se prestariam a uma hipotética redistribuição dos médicos, que se disporiam a prestar cuidados à população mais pobre e exigiriam níveis mais baixos de remuneração (já que não teriam investido tantos anos e recursos em seu processo de formação e que, na verdade, estariam prestando serviços simplificados).

Provavelmente (e há, como se viu, declarações explícitas a respeito) essa defesa intransigente da necessidade de terminalidade do curso de graduação foi um elemento decisivo para que o movimento por mudanças na educação médica nunca elaborasse propostas para a formação em nível de pósgraduação. A realidade é que se criou um sistema de formação em nível de Residência Médica capaz de absorver $70 \%$ dos médicos que se formam anualmente em nosso país. Mas como esse seria um investimento "irracional", não prioritário, ele foi praticamente desconsiderado pelos formuladores de propostas para a educação médica. As únicas tentativas de interferir no processo de formação na Residência foram os programas de Medicina Preventiva e Medicina Geral Comunitária, que não foram resposta suficiente às necessidades colocadas pela Reforma Sanitária em relação à formação de profissionais de saúde.

A defesa da terminalidade e a avaliação de que o processo de especialização profissional seria uma alternativa incorreta para nosso sistema de saúde teriam se constituído em alguns dos motivos para que a Residência Médica não fosse objeto da formulação de propostas em termos de estratégias de mudança na educação médica. Mas há outros elementos nesse processo.

Recentemente, o Ministério da Saúde vem investindo maciçamente no Programa de Saúde da Família. Certas correntes consideram que a saúde da família pode se constituir em um dos eixos da mudança de paradigma na saúde (Mendes, 1996). Nesse processo, está surgindo novamente a idéia de criar programas de Residência Médica em Saúde da Família como alternativa para formar "os profissionais necessários", um dos instrumentos de transformação do sistema de saúde.

Novamente (assim como na época da Medicina Preventiva), apresenta-se como alternativa ao modelo atual de formação dos médicos uma proposta que atinge somente uma parcela pequena dos recém-formados. Como se não fosse necessário trabalhar com a maior parte desse contingente de jovens médicos no sistema de saúde real. E como se fosse possível promover mudanças estruturais na saúde sem envolver a categoria médica.

Por trás desta omissão e da insistência em estratégias restritivas do ponto de vista da formação dos médicos (quer dizer, que atingem potencialmente uma parcela muito pequena dos recém-formados) poderia estar a dificuldade de relacionamento com a categoria médica tanto nos processos de mudanças na educação, como na implantação de reformas no sistema de saúde.

Muitas das correntes propositoras de mudanças na educação médica subestimaram o potencial de reconstrução da autonomia e da prática liberal. Desde o início dos anos 70 identificaram o processo crescente de 
assalariamento do médico e daí tiraram algumas conclusões. A primeira é que seria "a-histórica" a defesa da autonomia e, em conseqüência, politicamente insustentável ao longo do tempo. A segunda é que imaginavam que o processo de assalariamento estabeleceria uma relação de identidade (automática) entre médicos assalariados e trabalhadores $e$, conseqüentemente, entre médicos e população nas questões de organização do sistema de saúde e da educação médica, por exemplo (e então os médicos passariam a ser favoráveis à formação daquele generalista destinado a trabalhar na atenção primária).

Ou então, considerando a "diversidade da inserção dos médicos assalariados e dos demais trabalhadores tanto ao nível da estrutura produtiva, como também da diferente função social de suas práticas" se fazia a crítica a essas correntes que tentavam estabelecer relações de identidade automática entre essas categorias. Considerou-se então provável "que a intervenção dos médicos na política de saúde" se desse "principalmente objetivando a manutenção e a ampliação do exercício autônomo da profissão" (Campos, 1988).

A realidade revelou-se mais complexa e o comportamento político dos médicos também. Estes reconhecem a dupla natureza de sua inserção no mercado de trabalho: participam de movimentos por melhores salários, defendem a possibilidade de participarem do processo de capitalização da saúde como autônomos ou mediante cooperativas, defendem a saúde como um direito, o papel do Estado na garantia da prestação de serviços às camadas desprivilegiadas da população, o dever dos seguros-saúde de dar cobertura a todos os tipos de doenças etc.

A corrente política que conquistou a hegemonia nos movimentos médicos a partir da metade dos anos 80 foi a que se revelou "capaz de representar de forma eficaz os diferentes interesses de várias frações da categoria, diversidade esta produto da heterogeneidade com que se estrutura o mercado de trabalho dos médicos" (Campos, 1988).

Tanto em nível das propostas de mudança na educação médica como das políticas de saúde, existiu uma subestimação da importância e das possibilidades de intervenção do fator humano na produção de mudanças na saúde. Os homens, atores reais do processo, estavam esmagados sob o peso de muitas determinações estruturais: o complexo médico-industrial, o aparelho estatal, a instituição médica, o peso determinante do Estado e da infra-estrutura econômica na conformação das políticas sociais, a ordem médica, a estruturação do saber clínico (Campos, 1994).

Essa postura teórica, que influenciou grande parte do movimento pela Reforma Sanitária, certamente contribuiu para o fato de até recentemente os reformadores da saúde no Brasil não haverem se proposto a intervir na orientação do processo de educação dos profissionais de saúde (nem na graduação, nem na pós-graduação). O grau máximo de intervenção no processo de educação médica ficou reduzido ao veto do Conselho Nacional de Saúde à abertura de novas escolas.

Essas concepções teóricas também contribuíram para que houvesse pouca preocupação com a construção de uma nova prática sanitária e uma subestimação/negação da importância da prática clínica. A expropriação da 
saúde, a medicalização (entre outros) são processos reais, mas não podem levar à negação da existência da doença e do doente como problemas reais $e$ da clínica como um instrumento concreto de abordar a dor e o sofrimento individual.

Por todas essas razões, a Residência Médica, como palco privilegiado do treinamento clínico, não poderia mesmo ter sido alvo da preocupação e da elaboração dessas correntes em nível das políticas educacionais ou da formação de recursos humanos para a saúde.

\section{O desafio atual}

É interessante examinar o perfil atual do processo de formação propiciado pela Residência Médica para identificar quais seriam os elementos de uma proposta de transformação na área.

Alguns estudos, como o de Elias (1987), apontam a Residência Médica como uma opção para o treinamento profissional dos médicos que teria se fortalecido a partir da concepção flexneriana de educação médica. Por esse motivo, a Residência teria o hospital como local privilegiado para o treinamento prático dos médicos. No entanto, ao contrário do que Flexner defendia, são utilizados como campo de treinamento não somente os hospitais-escola, os hospitais universitários, mas também os hospitais da rede de serviços.

Hoje a Residência Médica produz médicos aptos para atuar fundamentalmente em nível hospitalar: unidades de internação, UTI $e$ urgência/emergência. A atividade ambulatorial já teve seu espaço ampliado em muitos programas, mas o que predomina ainda são os estágios em enfermarias, com o agravante de que o congestionamento dos serviços de apoio diagnóstico dos hospitais de ensino faz com que persista a deplorável categoria da "internação para investigação" (Feuerwerker, 1996).

Os hospitais onde ocorrem os programas de Residência, mesmo os que pertencem à rede pública de serviços, não se integraram de fato ao sistema de saúde. Existem evidências desse fato:

a) as prioridades de ação, as especialidades que existem em cada um deles $e$ as relações que estabelecem com a população de sua área de abrangência são definidos internamente, sem levar em conta os demais recursos existentes, a situação epidemiológica $e$ as prioridades de intervenção definidas pelas autoridades regionais de saúde;

b) apesar de prestarem serviços ao SUS, não há relações sistemáticas entre os hospitais e as demais unidades de saúde, levando a que os mecanismos de referência e contrarreferência não funcionem.

O processo de treinamento em nível da Residência Médica, como visto, tem tido seus rumos definidos num processo relativamente independente do que está ocorrendo no terreno da educação médica e também das políticas de saúde. São as necessidades das instituições que mantêm os programas $e$ os interesses da corporação médica os principais elementos definidores de suas características.

Os residentes têm poucas oportunidades de atuar com outros elementos das equipes de saúde, desconhecem o que seja a rede de serviços, seus 
recursos $e$ as atividades ali desenvolvidas. Vigilância epidemiológica, territorialização, planejamento local, trabalho com grupos, programas de promoção e prevenção são temas praticamente desconhecidos para eles. Os médicos que desenvolvem as atividades de preceptoria em muitos dos hospitais da rede de serviços não recebem qualquer aporte especial em seu processo de atualização, em sua capacitação pedagógica e tampouco estão familiarizados com a dinâmica das unidades não hospitalares.

Ora, o conteúdo da formação, da prática profissional e os cenários utilizados para treinamento durante a Residência Médica não podem ser indiferentes para os que tentam reorganizar as práticas sanitárias, nem para os que tentam implementar mudanças na graduação médica.

Pensar a Residência Médica como parte do processo de formação dos médicos pode ser um passo essencial para interferir de fato na definição do perfil dos profissionais médicos.

Um elemento central da atual crise da saúde é a necessidade de transformar as relações entre os médicos e os demais profissionais da saúde, entre os profissionais da saúde e a população, entre a população e sua própria saúde. A mudança dessas relações envolve transferência de poderes $e$ a redefinição da autonomia de todos esses sujeitos no processo da saúde e da doença.

A compreensão do processo saúde-doença como construção social redefine o terreno de ação $e$ a inserção dos serviços e dos profissionais de saúde. Como já foi dito, a ação intersetorial e social ganha papel preponderante nessa construção. Aí se dá a redefinição das relações dos sujeitos sociais com a saúde.

Mas, como já foi também discutido, essa revalorização da saúde não implica na negação da doença e da necessidade de se intervir sobre ela. Por isso é preciso redefinir também o espaço da doença, redefinir as relações dos sujeitos com seu processo de adoecer, sofrer e morrer. E é também necessário redefinir o papel da clínica e da ação específica não somente dos médicos, mas de todos os profissionais de saúde nesse campo.

Como momento privilegiado do treinamento clínico dos médicos e em função de sua interface com a prestação de serviços de saúde, a Residência Médica pode cumprir um papel importante nessa redefinição. Pode servir como cenário favorável à reorientação da interação/integração entre universidade e serviços e como palco da construção de novas práticas sanitárias.

Não se pretende com essa sugestão diminuir a importância das estratégias de promover mudanças na graduação: elas são fundamentais. $O$ problema é que o resultado das mudanças pode ser muito enfraquecido se não se considerar também a Residência Médica como palco necessário de transformações. Se a Residência tem hoje de fato um papel definidor em relação ao perfil do profissional formado, ela pode enfraquecer muito o impacto que as mudanças da graduação são capazes de produzir. E, ao contrário, o processo de mudanças na graduação pode ser potencializado ao se investir em mudanças na Residência Médica.

Neste momento de crise da saúde, a categoria médica encontra-se profundamente tensionada. Seu lugar social está ameaçado. A reconstrução 
da relação médico-paciente e saúde-coletividade estão no centro da crise atual. Por isso a categoria provavelmente esteja mais aberta à reflexão $e$ a proposições de mudança. Talvez esta seja uma oportunidade para que se produzam novos compromissos e novas relações.

Mas para isso é preciso interferir no processo. É preciso que todos os atores sejam considerados (o que não significa que todos os interesses possam ser conciliados) e que os problemas relacionados com a profissão médica sejam examinados em toda a sua complexidade, incluindo seu processo global de formação. Não se pode deixar esse terreno de ação somente para os setores interessados em rever o paradigma da saúde nos marcos da viabilização da acumulação capitalista no setor. É preciso romper os limites históricos e criar áreas de interação e possibilidades de diálogo com a categoria médica.

\section{Referências bibliográficas}

CAMPOS, G.W.S. Considerações sobre a arte e a ciência da mudança: revolução das coisas e reforma das pessoas. O caso da saúde. In: CECÍlIO, L.C.O. et al. Inventando a mudança na Saúde. São Paulo: Hucitec, 1994. Os médicos e a política de saúde. São Paulo: Hucitec, 1988.

ELIAS, P.E.M. Residência Médica no Brasil: a institucionalização da ambivalência. São Paulo, 1987. Dissertação (Mestrado). Departamento de Medicina Preventiva, Faculdade de Medicina, USP.

FEUERWERKER, L.C.M. e MARSIGLIA, R.G. Estratégias para mudança na formação de Rhs com base nas experiências IDA/UNI. Divulgação para Saúde em Debate, n.12, p.24-28, 1996a.

FEUERWERKER, L.C.M. Avaliação da residência Médica em São Paulo. In: Qualidade em Saúde, Cadernos FUNDAP, n.19, p. 153-169, 1996 b. As mudanças na educação médica $e$ a residência médica no Brasil. São Paulo, 1997. Dissertação (Mestrado), Departamento de Prática de Saúde Pública, Faculdade de Saúde Pública da Universidade de São Paulo.

FLEXNER, A. Medical Education in the United States and Canada. A report to the Carnegie Foundation for the advancement of teaching. New York, 1910.

FUNDAP. Análise do processo de seleção dos médicos-residentes do Estado de São Paulo, 1996.

FUNDAP. Distribuição da força de trabalho de nível superior na área da Saúde no Estado de São Paulo em 1992. Documento de Trabalho, 1997.

GALLO, E. Inovação, planejamento estratégico e gestão de qualidade nas escolas médicas brasileiras. In: Qualidade em Saúde, Cadernos FUNDAP, n.19, p.131-52, 1996.

KISIL, M. e CHAVES, M. Programa UNI: uma nova iniciativa na educação dos profissionais de Saúde, Battle Creek: Fundação W. K. Kellogg, 1994.

KISIL, M. Uma estratégia para a Reforma sanitária: a Iniciativa UNI. Divulgação em Saúde para Debate, n.12, p. 5-14, 1996.

KUHN, T.S. A estrutura das revoluções científicas. 3.ed. São Paulo: Perspectiva, 1995. 
MACHADO, M.H. et al. Perfil dos médicos. In: Dados, Fundação Oswaldo Cruz, n.19, 1996.

MARSIGLIA, R.G. Relação ensino/serviços : dez anos de integração docenteassistencial (IDA) no Brasil. São Paulo: Hucitec, 1995.

MENDES, E. V. Uma agenda para a saúde. São Paulo: Hucitec, 1996.

ORGANIZACIÓN PANAMERICANA DE LA SALUD. As transformações da profissão médica e a sua influência sobre a educação médica. In: Contribuições sobre a gestão de qualidade em Educação Médica, 1994a. (Série Desenvolvimento de Recursos Humanos, n.7).

PAIM, J. S. O SUS no ensino médico: retórica ou realidade. Anais do XXXIII Congresso Brasileiro de Educação Médica, 1995.

PICCINI, R. Avaliação do ensino médico no Brasil. Relatório Geral. CINAEM. 1997. (mimeo).

SCHRAIBER, L. B. O médico e o seu trabalho. São Paulo: Hucitec/ Rio de Janeiro: ABRASCO, 1993.

Educação médica e capitalismo. São Paulo: Hucitec/ Rio de Janeiro: ABRASCO, 1989.

WORLD HEALTH ORGANIZATION. Changing medical education and

practice: an agenda for action. Genebra, 1991. (WHO/EDUC/91.200). 


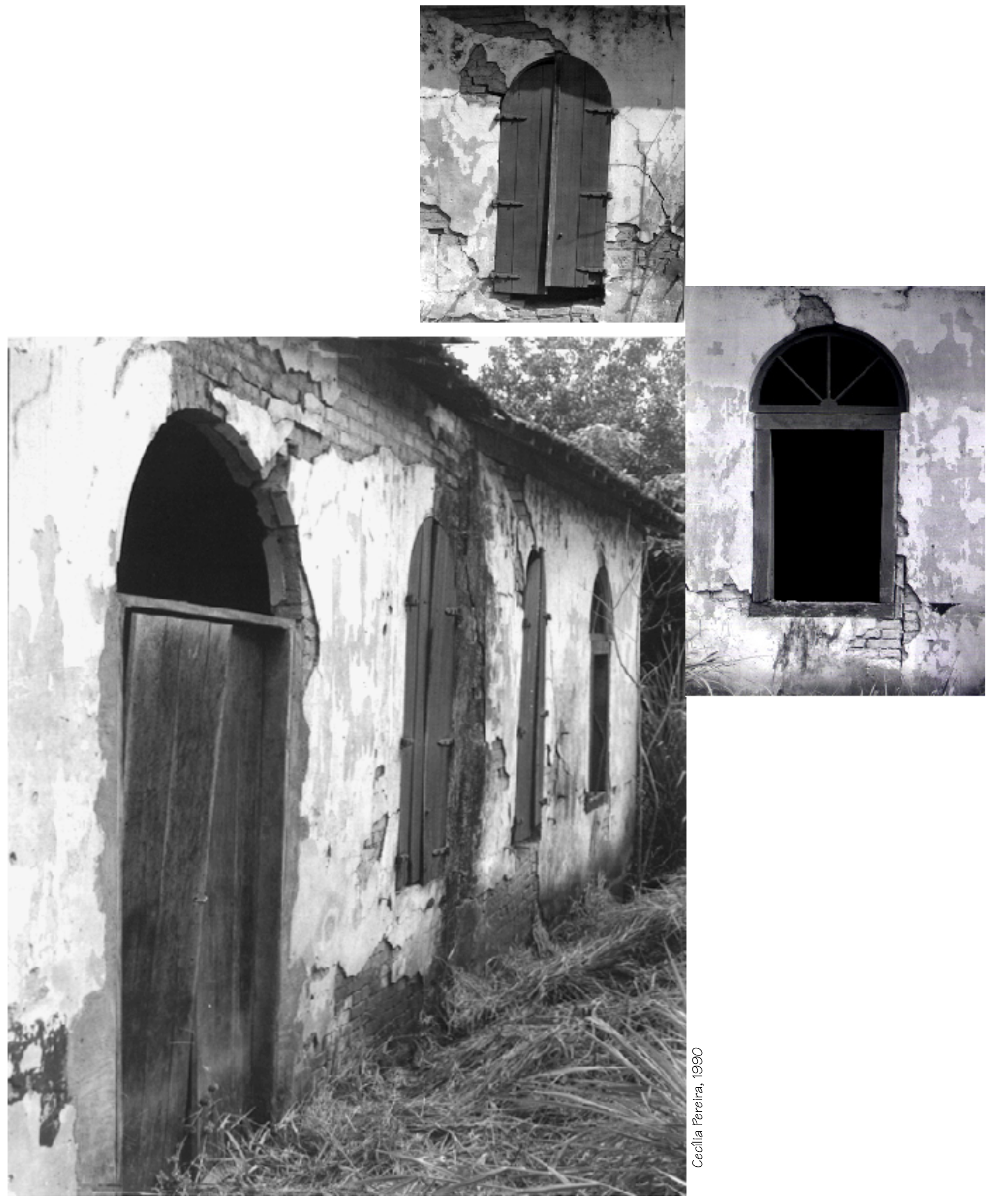

